\title{
Auxiliary Verbs in Serbo-Croatian, French, Persian, Spanish and English: A Cognitive-Semantic Approach to the Auxiliary Verb Usage and Passive Voice
}

\author{
Rajdeep Singh ${ }^{1}$ \\ ${ }^{1}$ Department of Linguistics, Payame Noor University, Tehran, Iran \\ Correspondence: Rajdeep Singh Department of Linguistics, Payame Noor University, Tehran, Iran.
}

Received: June 11, 2018

Accepted: August 31, 2018

Online Published: September 19, 2018

doi:10.5430/elr.v7n3p34

URL: http://dx.doi.org/10.5430/elr.v7n3p34

\begin{abstract}
Auxiliary verbs have an important influence in the way languages connect with the cognitive processes. In this study, we investigate the role of auxiliary verbs in the formation of the semantic picture we get from their usage. Furthermore, the semantic notion and its interaction with the cognitive processing are taken into account. For our goal to be more tangible and testable, we took Serbo-Croatian, Persian, Spanish, French and English for an in-depth analysis, wherefrom we proposed a classification scheme for all languages based on the behavior of their auxiliary verbs. Based on the proposed model, we investigate furthermore the passive voice in English and propose a strong explanation for the cognitive-semantic sense of the passive in English based on the cognitive duality principle. Importance of Croatian in the way that it forms an extreme pole in the proposed classification scheme is further discussed. Furthermore, it is demonstrated that Persian has a syntactic incorporation in its simple past and present perfect.
\end{abstract}

Keywords: Serbo-Croatian, auxiliary verb, syntactic incorporation, Persian, passive voice, cognitive, semantics, Croatian syntax, Spanish, French

\section{Introduction to the Auxiliary Verbs and Passive Voice}

Auxiliary verb usage for the past tense is one of the fundamental features of languages belonging to the Indo-European language family. Bybee and Pagliuca (1985) in a cross-linguistic comparison make important correlations between languages which are close to each other based on the semantic and grammatical meaning. They propose a characterization of certain aspectual and modality categories in order to generalize semantics in grammatical meaning. In our study as well, we will begin with the comparison of languages in order to explain the phenomenon of dual modal verb usage in different languages. Senay, Usak and Prokop (2015) focus on self-talk and passive voice and their role in improving task performance. In fact, they investigate the cognitive processing associated with the passive voice in different languages and the task performance improvement. Singh (2018) considers the language change as a rather predictable phenomenon and proposes a model which can help predicting the areas with the highest changes in future. He furthermore brings concrete examples of changes in Persian and Kurdish which confirm his hypothesis. Macdonald (2017) argues for the presence of an implicit projected argument in Spec,Voice in Spanish impersonal and passive "se" constructions; he presents further empirical support which comes from the clear possession interpretation of the sole overt DP. Hansen (2000) investigates how the German modal verb influenced the Slavic language usage of the modal verb by proposing a reconstruction from Slavic languages to German. In our study, however, we go beyond case by case only study of the correlation between Slavic and German languages, and try to capture the whole picture when it comes to the auxiliary verb usage. Singh (2018) conducts an error analysis on the learners of Hausa in order to account for the compounding error. Compounding error and the cognitive processes behind it is further highlighted. Our study also can lead to predict some of the errors when it comes to the auxiliary verb usage. Goldberg (2005) works on the VP-stranding which happens in many languages and investigates the VP ellipsis across languages and points out to the importance of auxiliary verbs when it comes to the VP-stranding. We will rather work on the auxiliary verbs from the cognitive-semantic perspective, instead of the syntactic approach, and our study tries to explain the reason behind the auxiliary verb differences in usage across languages, instead of merely describing it. Singh (2018) investigates the role of spatial prepositions in Persian and Norwegian in order to put emphasis on the interplay between cognitive and syntactic 
features. In our study, we look also at the syntactic feature to find out the cognitive processing behind it. Borsley and Rivero (1994) investigate the clitic auxiliaries and their incorporation in a Slavic language, namely polish, while they emphasis the fact that polish past tense is a combination of past participle and perfect auxiliary. In our study, we also claim that Persian past tense is a case of syntactic incorporation. Singh (2018) proposes an interesting model, mirroring effect and water code, to account for the cognates and word formation in the sacred context, where mirroring effect refers to the way the sacred and cultural words are inversely constructed. Again, the same emphasis on the cognitive and semantic side is exactly what we search for and try to account for in the auxiliary verbs. Dabir-Moghaddam (1997) investigates the compound verbs and compound verb formation processes in Persian and suggests many different processes which all can be classified under the compounding. In a similar fashion, we look at the auxiliary verb usage in Persian and investigate how the auxiliary verb gets incorporated in the verb as well. Ackema and Čamdžić (2003) suggests a novel approach to the situation where the participle precedes the auxiliary in Slavic languages, including Croatian, and consider this as head-to-head movement rather than a long head movement. In our study, we are more concerned with the way the auxiliary verbs are chosen in different languages, including Slavic branch, and we look for an explanation for the different auxiliary choices across languages. Singh (2018) brings the notion of basket verb in order to investigate the inflection in several languages, including Persian, Spanish, Swahili and English. However, we will just concentrate on the syntactic-cognitive interplay in the auxiliary verbs and do not concern over the inflection. Baker, Johnson, and Roberts (1989) suggest ways to deal with the passive arguments inside the government-binding theory. However, we look at the passive voice from the cognitive perspective and bring evidence for the interplay between cognitive and syntactic approaches in the passive formation. Schmitt (2001) works on the interesting case of the Portuguese present perfect and the variation observed compared to other romance languages and proposes the property of forcing iteration to account for this. Singh (2018) analyzes the semantic and function loads of word in order to take into account the blurred semantics in the sacred words. We also look at the semantics of auxiliary verbs in the broader context just as in the passive voice. Wechsler and Zlatic (2000) investigate the agreement theory and the lexical features of nouns that are related to this theory, as well as the mixed agreement in the case of Serbo-Croatian. However, what we are more interested in is rather how the cognitive processing is affected by the mixed agreement. In our study, by working on the auxiliary verbs in Croatian, we come up with a cognitive explanation as well as syntactic one. Margan, Martinčić-Ipšić and Meštrović (2014) investigate the different network properties of normal and shuffled Croatian texts. Furthermore, they concluded that syntax plays a significant role in Croatian, despite being a mostly free-word order language. In our study, we put more emphasis on the syntactic role of auxiliary verbs in Croatian and the link to the cognitive processing.

\section{Croatian and Persian: The Same Auxiliary Verb Usage}

Croatian and Persian are both of Proto Indo-European language family and we find many similar features in them. However, when it comes to the syntax, we see a big divergence. In fact, the Croatian syntactic features are quite distinct which makes it an important language to discuss since it may have the keys to the wider differences we see today between Indo-European languages, from Indian Sanskrit to English and German. In this study, we try to account for those differences through the investigation of the main features in different languages, including Persian and Croatian. In Croatian, one important features of the past tense is the usage of the verb biti (to be) with the perfect participle. This is definitely interesting since in English and many other Indo-European family languages the verb to have is used. So this makes the Croatian a very different language in the verb component of the syntax. However, in Persian, there is also some way to get to the Croatian way of past tense verb formation. By looking at some examples the similarities come to the attention. Example 1 and 2 are to be considered and in following examples the PP, INF, PL, SG, PERF, and PREP stand for the past participle, infinitive, plural and singular, perfective tense, and preposition respectively.

Example1.

Ja Sam radio

I-1ST-SG Am-AUX-1ST-SG worked-PP (I worked, or I have worked)

Ona je radial

$\begin{array}{lll}\text { She- } 3 R D-S G \quad \text { is- } A U X-3 R D-S G \quad \text { worked- } P P & \text { (She has worked.) }\end{array}$ 
Example2.

Man

rafteham

I-1ST-SG

have gone-PERF-1ST-SG

(I have gone.)

Oo kar kardeast

She-3RD-SG work- $O b j$ have done-PERF-3RD-SG

(She has worked.)

Following the above-mentioned examples, it is still hard to see how the Persian examples in Example2 can be related to the Croatian examples in Example1. In order to show the link, we analyze the Persian present perfect verb by dividing it further in a way so that the extraordinary similarity can be explained.

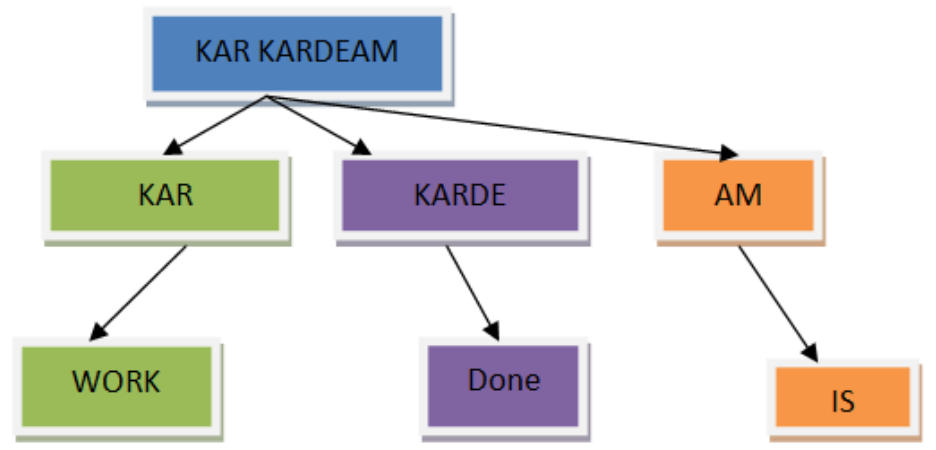

Figure 1. Analysis of the Persian perfect tense "kar kardeam" (I have worked).

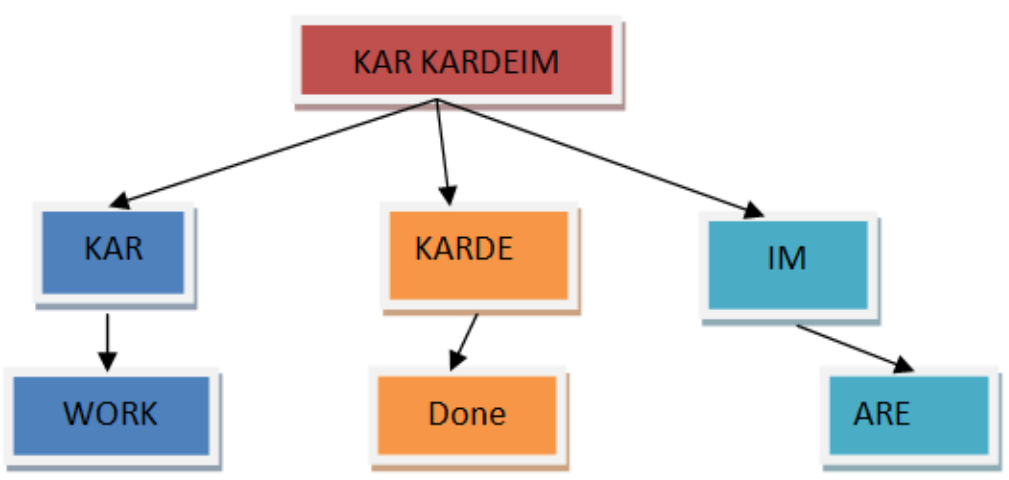

Figure 2. Analysis of the Persian perfect tense "kar kardeim" (we have worked).

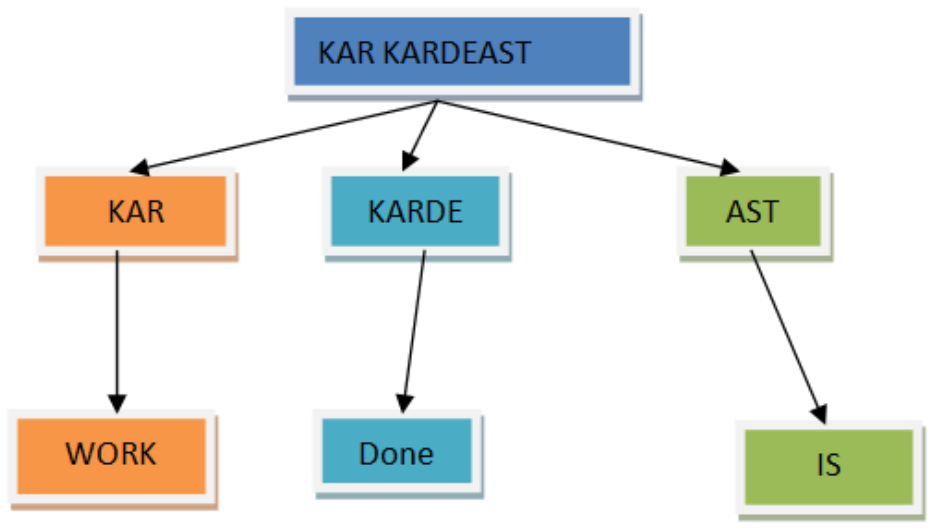

Figure 3. Analysis of the Persian perfect tense "kar kardeast"(she/he has worked).

As it is shown in the above figures, by the disassembly of Persian verbs, we have the cognate form of Croatian past verb formulation in Persian present perfect. This shows that Persian uses the syntactic incorporation for the present perfect. 


\section{Syntactic Incorporation in Persian}

In fact, we observe that Persian has a unique feature of having the syntactic incorporation in the simple past tense as well. That's where Persian behaves similar to polish. Investigating the Persian simple past will give more insight to the way auxiliary verbs are used in Persian. With some examples, the situation can become clearer. Let's consider Example3 to clarify the point.

Example3.

Man amadam

I- $1 S T-S G$

came- Simple Past-1ST-SG

(I came.)

MA

RAFTIM

We- $1 S T-P L$

left-Simple Past-1ST-PL

(We left.)

If we analyze the verb formation in the Persian simple past by dividing the main verb, we will notice the fact that it is also formed by incorporating the past principle with the auxiliary verb, in a way that is even more compact than the present perfect. Here below, we provide the analysis for the simple past in Persian in Figure4 and Figure5.

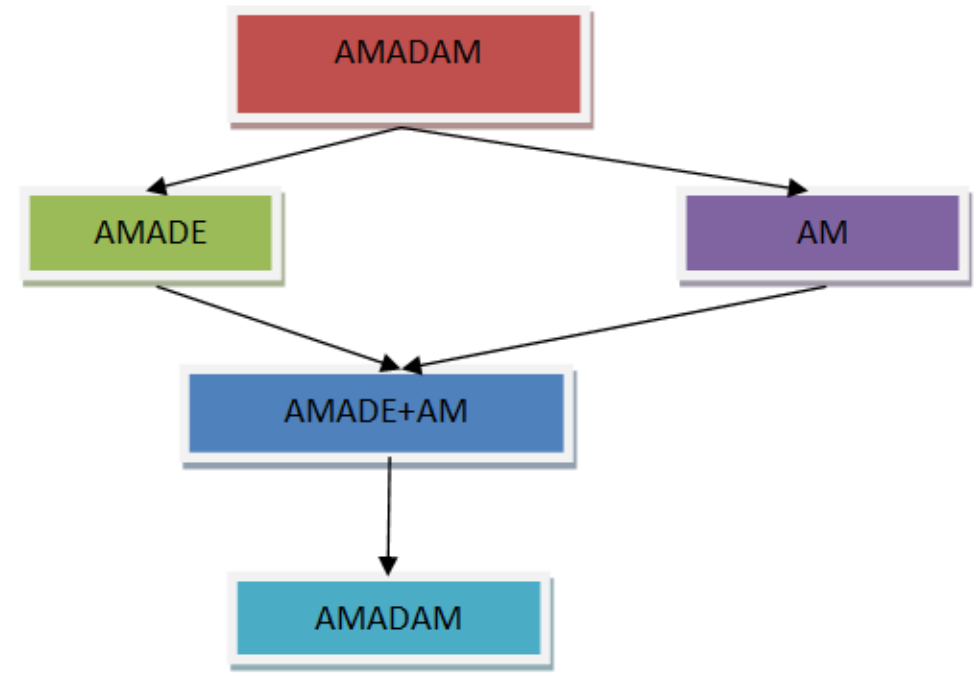

Figure 4. Analysis of the simple past "amadam" (I came)

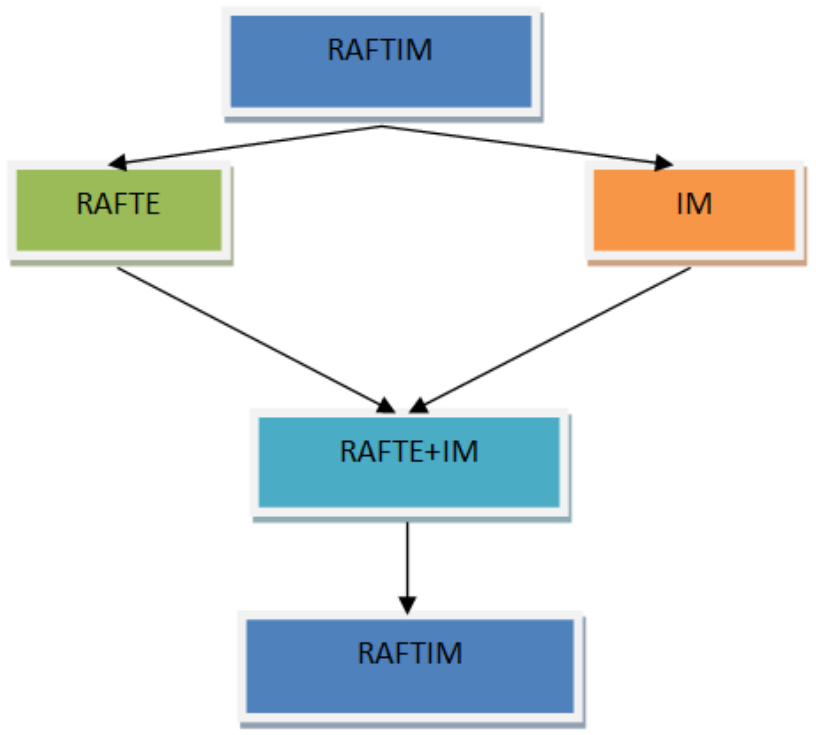

Figure 5. Analysis of the Persian simple past "raftim" (we went)

As we can clearly see, the Persian simple past is in fact a more compact form of syntactic incorporation. This is 
definitely unique as we earlier pointed out to the Persian present perfect, which has the notion of past in its core, has the syntactic incorporation feature. Therefore, Persian is special as it uses the syntactic incorporation in a very systematic way.

\section{Aux Language Classification}

When we consider the language processing in the cognitive level, then we expect to find a rather general, systematic usage of modal auxiliary verb usage for the past tense. In fact we can look at different languages and classify them based on the very important notion of past tense verb formation and the usage of the auxiliary verbs, to be and to have, as an important temporal-spatial factor in the cognitive processing. We call this type of language classification as Aux classification, where Aux stands for Auxiliary based classification. Let's consider French and English to see if we can further refine our findings regarding the type of auxiliary verb involved. French uses an interesting combination of the two verbs, to be and to have, in order to form the past tense. Italian shares this property with French. On the other extreme, English makes use of the verb to have for the past tense formation. Example 4, 5 and 6 are to be considered for the better understanding of the trend in French, Spanish, and English, respectively.

Example4.

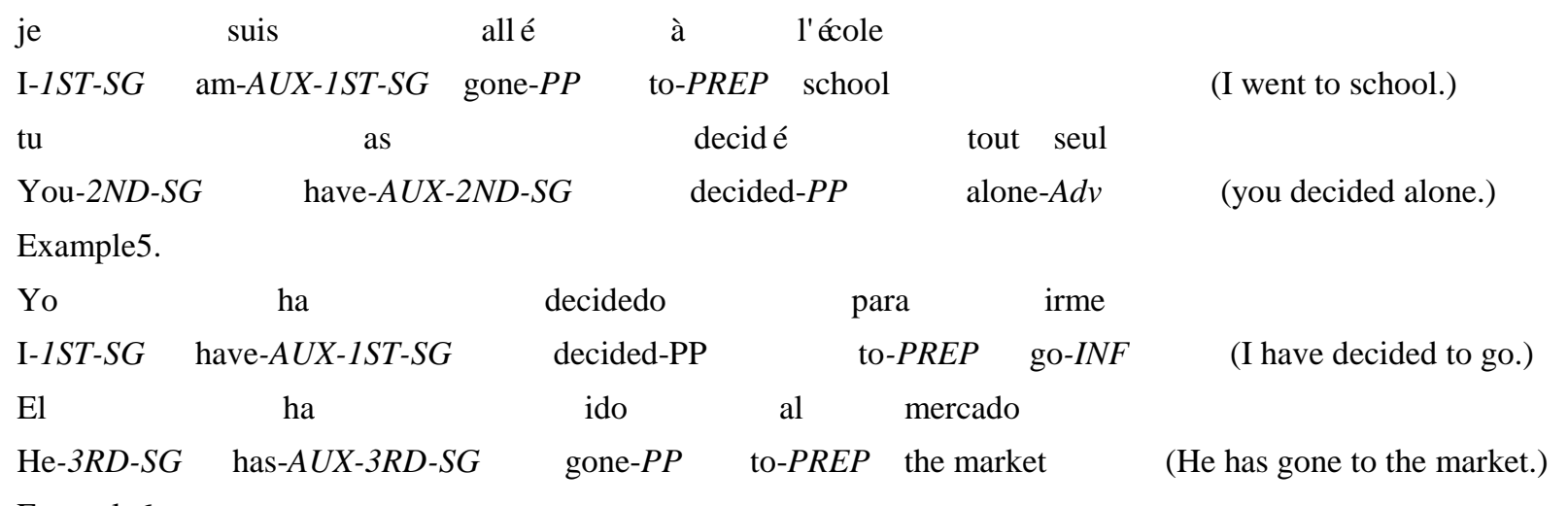

Example6.

I have done this.

I have gone to the market.

Following the examples above, it gets clear that French is in the middle of the modal auxiliary verb usage, using both verbs, to be and to have. Croatian is on one extreme, using only the modal auxiliary verb to be. While Spanish and English are at the other extreme, using only the verb to have. Therefore, so, the Aux classification which is the classification of languages based on the specific modal verb usage of their past tense is as follows:

B languages (B type): languages where the verb "to be" is used as the auxiliary verb for the past tense.

$\mathrm{H}$ languages (H type): languages where the verb "to have" is used as the auxiliary verb for the past tense.

BH languages (BH type): languages where the verbs "to be" and "to have" are used as the auxiliary verb for the past tense.

Occult languages (O type): languages where they can be considered as B, H, or BH languages by disassembling their verb component in the past tense.

Aux classification is illustrated in Figure6, where we have a much broader classification of languages based on the auxiliary verb type. 


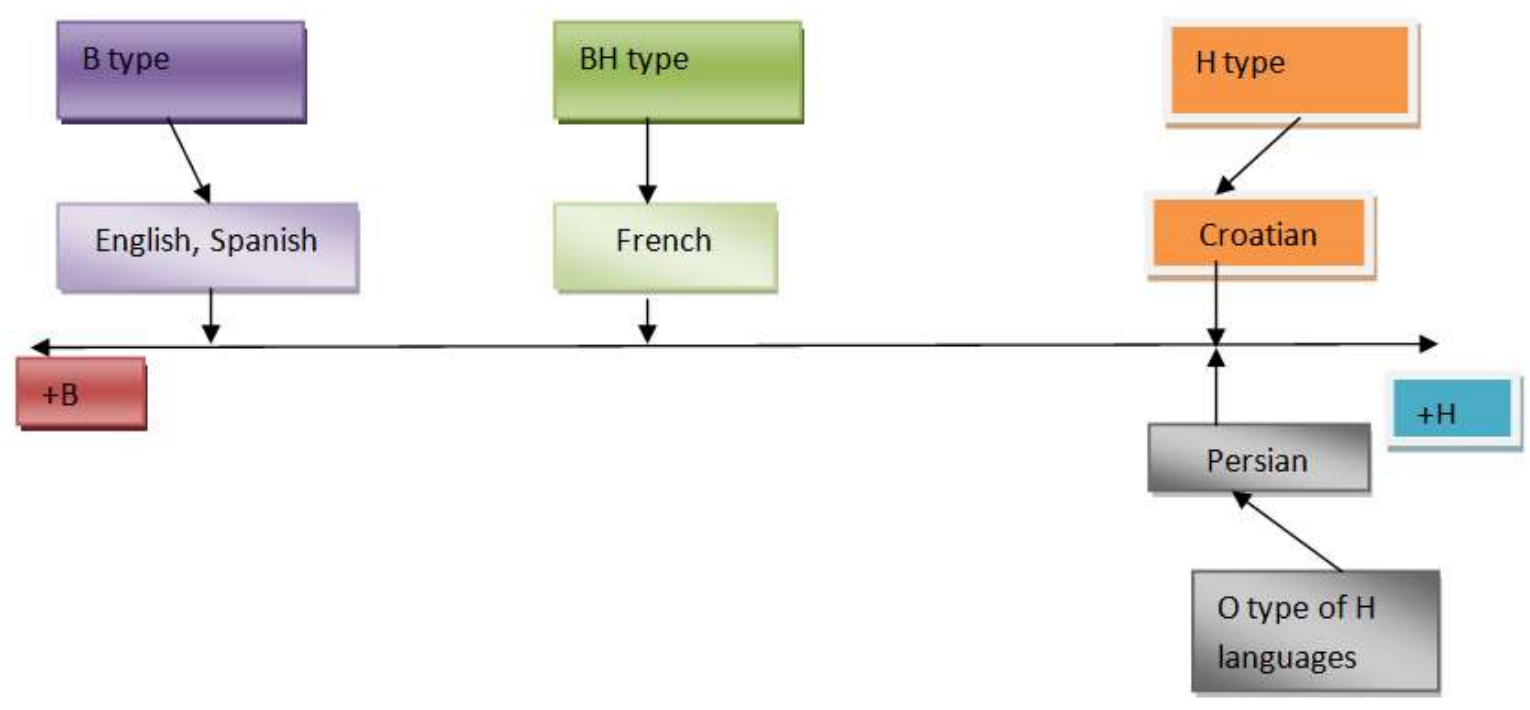

Figure 6. Aux Language classification

Aux classification shows that auxiliary verb is an important source for the insight we get about the languages and how they relate themselves with the spatial-temporal dimension. It is not surprising that we see such a systematic behavior of languages based on the auxiliary verbs. This definitely can lead us to a deeper semantic-cognitive analysis of languages.

\section{Cognitive Duality Principle: Process-Oriented vs. End-Product Oriented}

Here, we will show how the Aux classification can account for the way each language relates to the environment wherein they strive to develop and survive. When we have a B type language, then there is covert semantic meaning of the temporal end goal. In fact, in B languages, where we have the verb "to be" as the auxiliary verb for the past tense, the speaker rather look at the final output, without considering the process before it. Example 7 can help clarifying the situation for Croatian which is a B type language.

Example7.

otišao sam jučer

Gone- $P P$

am- $A U X-1 S T-S G \quad$ yesterday- $A d v \quad$ (I went yesterday.)

Sam kupio jabuku

Am-AUX-1ST-SG bought-PP apple-Obj (I bought apple.)

In Example7, we can analyze the sentence meaning as follows:

Analysis of Example7:

Otišao

sam

jučer

Gone- $P P$

am- $A U X-1 S T-S G$

yesterday- $A d v \quad$ (I am while yesterday I visited there.)

Sam kupio jabuku.

Am-AUX-1ST-SG bought-PP apple-Obj (I am with the bought apple.)

As the above analysis shows, with B type languages, the speaker places himself with the end product, i.e. the rest of the sentence. Now, let's consider the Example8 from Spanish which is an H type language.

Example8.

He comprado una manzana

Have-AUX-1ST-SG bought-PP an apple-Obj (I have bought an apple.) 


\begin{tabular}{|c|c|c|c|c|}
\hline $\mathrm{He}$ & ido & a & las montañas & \\
\hline Have- $A U X-1 S T-S G$ & gone- $P P$ & to-PREP & the mountains & (I have gone to the mountains.) \\
\hline
\end{tabular}

We can analyze the example 8 as follows:

Analysis of example6:

$\mathrm{He}$

Have-AUX-1ST-SG

$\mathrm{He}$ ido

$$
\text { comprador }
$$$$
\text { bought- } P P
$$$$
\text { do a }
$$

una manzana

an apple- $O b j$

las montañas
(I have the bought apple.)

Have-AUX-1ST-SG gone-PP to-PREP the mountains (I have the experience of going to the mountains.)

In the analysis of the $\mathrm{H}$ type languages, as mentioned above, the speaker places himself/herself through the process of the whole sentence. Therefore, $\mathrm{H}$ type languages are rather process oriented. This results in a novel principle of cognitive duality. Cognitive duality principle states that cognitive processing follows a binary model where the process oriented and end oriented paths are to be seen as the two extreme poles. However, it is not a strict binary model, and therefore, there are languages that use the both orientations to put emphasis on one of them due to the conditions. For example, while English is a process oriented language, it chooses the end oriented path for the passive voice.

\section{Passive Voice: The Conversion Instrument}

In order to show this process-oriented/end-product oriented split, we can consider the active/passive split in English. In fact, the passive voice in English is a great usage of converting an $\mathrm{H}$ type verb to a B type verb and can be very explanatory for the process-oriented versus end oriented notion. Let's consider example9 in order to clarify the passive involvement in our analysis.

Example9.

He has done it. (He has the result through the action.)

It is done. (The situation is placed with the end result.)

As it is shown in the above example, in the passive sentence, which is in fact a form of B type, the speaker does not care about the process, but she is concerned with the end-product. Therefore, our analysis can become richer when we look at the passive voice in English as the remnant of possible $\mathrm{H}$ type mother language, which is no longer there. The English passive voice, indeed, shows that even in an $\mathrm{H}$ type language, we can encounter situations where the emphasis is put on the end-product, instead of the process. Therefore, with the conversion (H type to B type), we explained why the passive formation is so different compared to other voices and this change of the nature is an important way to show how the function of modal verbs is different.

\section{Conclusion and Result Discussion}

Aux classification brings so much insight to the way languages differ and it shows much deeper cognitive and semantic notions. As it is shown in this study, auxiliary verbs put on evidence a cognitive processing which can lead to a language where the emphasis is put on the process and to another language where the end product has more implications and emphasis. This duality of process and end product shows itself well in the way languages make use of the auxiliary verbs available to them. Some languages, such as French, show a very flexible stance, while others are pretty one sided. From this, we showed how passive voice can be explained and accounted for by the mere auxiliary verb usage and the duality of process and the end goal. This is a novel idea as it explains the semantic notions behind the passive verbs. The fact that we could account for the semantics of the passive voice by cognitive duality principle is of importance. Another important point was made regarding the Persian special syntactic feature and that was the syntactic incorporation. We showed how Persian in a great deal uses the syntactic incorporation. Croatian was the key to the Aux language classification since it is one of the few languages where it almost exclusively uses one extreme pole on the auxiliary verb range. In fact, it shows how the end product is important semantically to the Croatians and how the process is less emphasized compared to the end product. On the other hand, English thought is more process oriented and the end product is cognitively less stressed. Definitely further investigation to the interpretation of this study can lead to the better understanding of the psychological aspects of language use and ways to influence the mind in a more systematic way. 


\section{References}

Ackema, P., \& Čamdžić, A. (2003). LF complex predicate formation: The case of participle' fronting in Serbo-Croatian. UCL Working Papers in Linguistics, 15, 131-175. Retrieved from: https://www.phon.ucl.ac.uk/publications/WPL/03papers/ackema_camdzic.pdf

Baker, M., Johnson, K. \& Roberts, I. (1989). Passive arguments raised. Linguistic Inquiry, 20, 219- 251. Retrieved from: https://www.jstor.org/stable/4178625

Borsley, R., D. \& Rivero, M., L. (1994). Clitic Auxiliaries and Incorporation in Polish. Natural Language and Linguistic Theory, 12, 373-422. https://doi.org/10.1007/bf01118135

Bybee, J. \& W. Pagliuca (1985). Cross-linguistic comparison and the development of grammatical meaning. In Fisiak, J. (ed.), Historical semantics. Historical word formation. Berlin: Mouton de Gruyter. 59-83. https://doi.org/10.1515/9783110850178.59

Dabir-Moghaddam, M. (1997). 'Compound Verbs in Persian'. Studies in the Linguistic Sciences, 27(2), 25-59. Retrieved

from: https://www.ideals.illinois.edu/bitstream/handle/2142/11586/SLS1997v27.2-05DabirMoghaddam.pdf

Goldberg, L., M. (2005). Verb-stranding VP ellipsis: A cross-linguistic study. Doctoral dissertation, McGill University, Montreal. Retrieved from: http://digitool.library.mcgill.ca/webclient/StreamGate?folder_id=0\&dvs=1536569386550 229

Hansen, B. (2000). The German modal verb müssen and the Slavonic languages - The reconstruction of a success story. Scando-Slavica, 46, 77-92. https://doi.org/10.1034/j.1600-082x.2000.d01-7.x

Macdonald, J. (2017). An Implicit Projected Argument in Spanish Impersonal-and Passive-Se Constructions. Syntax, 20(4), 353-383. https://doi.org/10.1111/synt.12146

Margan, D., Martinčić-Ipšić, S. \& Meštrović, A. (2014). "Network differences ' between normal and shuffled texts: Case of Croatian," Springer. Studies in Computational Intelligence, Complex Networks V, 549, $275-283$. https://doi.org/10.1007/978-3-319-05401-8_26

Schmitt, C. (2001). Cross-linguistic variation and the present perfect: the case of Portuguese. Natural Language and Linguistic Theory, 19, 403-453. https://doi.org/10.1023/a:1010759911058

Senay, I., Usak, M., \& Prokop, P. (2015). Talking about behaviors in the passive voice increases task performance. Applied Cognitive Psychology, 29(2), 262-270. https://doi.org/10.1002/acp.3104

Singh, R. (2018). Derivational Grammar Model and Basket Verb: A Novel Approach to the Inflectional Phrase in the Generative Grammar and Cognitive Processing. English Linguistics Research, 7(2). https://doi.org/10.5430/elr.v7n2p9

Singh, R. (2018). A Cognitive Approach to the Semantics in the Sacred Context: Semantic and Symbolic Function of Sacred Words. English Linguistics Research, 7(3). https://doi.org/10.5430/elr.v7n3p1

Singh, R. (2018). Norwegian and Persian spatial prepositions: a novel comparative and syntactic approach to the spatial prepositions. KAAV international journal of English, literature, and linguistics, vol.5/ page no.1-8. Retrieved from: http://www.kaavpublications.org/journals/journal-5/abstract/abstract-1788.pdf

Singh, R. (2018). Language change and directionality: A novel model for language change in Persian and Iranian languages from the sociolinguistic perspective. KAAV International journal of English, Literature, and linguistics,.5, 1-8. Retrieved from: www.kaavpublications.org/journals/journal-5/article/article-1876.pdf

Singh, R. (2018). Error Analysis of Persian Learners of Hausa Language: Cognitive Approach to Errors. Journal of Literature, Languages and Linguistics, 45, 10-15. Retrieved from: https://iiste.org/Journals/index.php/JLLL/article/viewFile/42853/44147

Singh, R. (2018). Mirroring Effects and the Water Code: A Cognitive-Semantic Approach to Natural Morphology in the Religious-Cultural Context. Journal of Literature, Languages and Linguistics, 46, 37-41. Retrieved from: https://iiste.org/Journals/index.php/JLLL/article/download/43453/44769

Wechsler, S. \& Zlatić, L. (2000). A theory of agreement and its application to Serbo-Croatian. Language, 76, 799-832. https://doi.org/10.2307/417200 